\title{
OS SABERES DA TRADIÇÃO DA COMUNIDADE SEGREDINHO NA PERCEPÇÃO DAS CRIANÇAS
}

\author{
Nádia Araújo Rocha ${ }^{1}$ \\ Ariadne da Costa Peres Contente ${ }^{2}$
}

\begin{abstract}
RESUMO
Este artigo se propõe a refletir sobre os saberes da tradição que são apreendidos por meio da pesca artesanal e o mito que envolve o Lago do Segredo a partir da percepção das crianças da comunidade Segredinho/Capanema-PA. Trata-se de um recorte da pesquisa de doutorado que está sendo desenvolvida na comunidade Segredinho/Capanema-PA no nordeste paraense. Para isso, utilizou-se a pesquisa qualitativa e para a obtenção dos dados a entrevista semiestruturada com duas (02) crianças moradoras da comunidade. Os resultados apontaram que as crianças desenvolvem cotidianamente na realização de práticas socioambientais saberes ligados a: composição, tamanho, tipo dos peixes, os instrumentos de pesca, a identificação das espécies, os pontos mais propícios para a pesca e etc. Saberes referentes a pesca artesanal adquiridos por meio da transmissão e da observação dos mais experientes na atividade, que passa de geração para geração. A pesca no Lago do Segredo além de ser uma atividade econômica congrega aspectos míticos, simbólicos e da tradição.
\end{abstract}

Palavras-Chave: Saberes da tradição. Pesca artesanal. Lago do Segredo.

\section{TRADITIONAL KNOWLEDGES OF SEGREDINHO COMMUNITY THROUGH CHILDREN'S PERCEPTION}

\begin{abstract}
This article aims to reflect on the traditional knowledge learned through artisanal fishing and the myth that involves the Segredo Lake from the children perception in the Segredinho community, CapanemaPA. This article is a part of the doctoral research in the Segredinho community, Capanema-PA in the northeastern Pará. Qualitative research was used and the data was obtained through a semi-structured interview. This interview was directed at two (02) children living in this community. The results showed that children develop knowledge linked to the composition, size, type of fish, fishing instruments, identification of species, the most suitable points for fishing and other through of socio-environmental practices knowledge daily. The artisanal fishing knowledge is acquired through the transmission and observation of the most experienced in the activity, which passes between generations. Fishing in Segredo Lake besides that an economic activity, unite mythic, symbolic and tradition aspects.
\end{abstract}

Keywords: Traditional knowledge. Artisanal fishing. Segredo Lake.

Data de submissão: 05.10 .2020

Data de aprovação: 15.12 .2020

\section{INTRODUÇÃO}

Nos dias atuais, as questões econômicas, sociais, ambientais estão interligadas, dentro de uma dimensão conjunta, transdisciplinar. Assim, requerem a produção de um conhecimento que discuta todas essas demandas e crie laços, integrando a filosofia, a arte, política, estética, ética e etc.

\footnotetext{
${ }^{1}$ Mestre em Gestão de Recursos Naturais e Desenvolvimento Local, Técnica em Assuntos Educacionais no Campus Universitário de Bragança- Universidade Federal do Pará. E-mail: nrocha@ufpa.br.

${ }^{2}$ Doutora em Ciências Sociais, Professora Adjunta III na Universidade Federal do Pará. E-mail:ariadne@ufpa.br.
} 
A produção do conhecimento se constitui, cada vez mais, numa trama de relações complexas, exigindo um trabalho integrador, novas formas de interação comunicativa entre as diferentes áreas do saber (SILVA, 2010). Não podemos mais insistir numa concepção de conhecimento que se isole das dimensões gerais em que este está sendo constituído, ou então, que se mantenha com uma visão unitária do contexto social em que os acontecimentos são produzidos.

É necessário compreender que existem outros saberes, diferentes modos de explicar, conceber e construir a realidade. Saberes que são constituídos nas bases da cultura, da vivencia e de práticas tradicionais ainda presentes em muitas comunidades do nordeste paraense.

Trata-se dos saberes míticos, locais e/ou socioambientais adquiridos por meio da convivência e da interação do homem com a natureza. E são imprescindíveis para o entendimento e o desenvolvimento dos modos de vida das comunidades que ainda se organizam a partir de práticas socioambientais a exemplo da pesca, a agricultura, o extrativismo e etc.

Tais práticas são imprescindíveis dentro das relações econômicas e culturais para muitas comunidades tradicionais e desenvolvem uma diversidade de saberes em contato com a natureza, que influenciam seus modos de vida, a cultura e identidade dos moradores, como apontam estudiosos como ALMEIDA (2010); DIÉGUES (1994); SILVA (2010); FURTADO (1993).

Porém, diante das mudanças imposta por paradigmas capitalistas provocando uma nova relação entre o ser humano e a natureza gerando transformações relacionadas ao consumo e aos modo de produção, muitas comunidades tradicionais ao se adaptar aos elementos ditos modernos e tecnológicos, deixam para traz suas raízes e seus saberes e as novas gerações silenciam os ensinamentos de seus ancestrais, suprimindo sua cultura pela adoção de valores racionais e hegemônicos.

Esse pressuposto, conduziu-nos a refletir os saberes da tradição no contexto da comunidade Segredinho a partir das seguintes questões de pesquisa: que saberes da tradição as crianças da comunidade segredinho possuem advindos das relações estabelecidas com o Lago do Segredo? Quais as percepções que as crianças possuem a respeito dos saberes da tradição e do mito que envolve o índio encantado no Lago do Segredo?

Estudos anteriores de Rocha (2011) apontaram a relação econômica e cultural que a comunidade Segredinho tem com a pesca artesanal e a relevância dos saberes da tradição adquiridos por meio desta atividade. Porém, nesse artigo, sentiu-se a necessidade de evidenciar tais saberes por meio das compreensões das crianças.

A comunidade Segredinho geograficamente está localizada no nordeste paraense, há 24 $\mathrm{km}$ do município de Capanema-PA. A principal atividade econômica desenvolvida é a pesca artesanal que é realizada em um lago que fica próximo da comunidade, sendo este o motivo principal que desencadeou a formação das residências e posteriormente a constituição da comunidade.

O lago do Segredo é considerado pelos moradores um lugar mítico, para eles existe a presença de um ser encantado nesse espaço, um índio, que sumiu a muitos anos atrás por ter escondido o segredo sobre a existência do lago. Sendo assim, os moradores conservam este mito alegando ser o índio encantado responsável pela conservação dos recursos naturais presentes no ambiente, reproduzindo suas práticas de acordo com esta crença e transmitindo entre as gerações por meio das histórias que envolvem mistério, imaginação e simbolismo.

Acreditam na influência dos seres mágicos a manutenção e o cuidado com o ambiente natural e divulgam suas histórias por meio de suas narrativas. Além disso, o Lago é o ambiente onde é realizada a atividade da pesca artesanal, que é desenvolvida por homens e mulheres e por muito tempo algumas famílias sobreviveram apenas com os recursos extraídos de lá (ROCHA, 2011). 
Assim, este artigo objetiva refletir sobre os saberes da tradição que são apreendidos por meio da pesca artesanal e o mito que envolve o Lago do Segredo a partir da percepção das crianças da comunidade Segredinho/Capanema-PA. Trata-se de um recorte da pesquisa de doutorado que está sendo desenvolvida na comunidade Segredinho/Capanema-PA. Para isso, utilizou-se a pesquisa qualitativa por esta "levar em consideração as subjetividades dos sujeitos e seu contexto histórico-social, buscando responder as questões intrínseca a dimensão social dos sujeitos" (MINAYO, 2016, p.34).

Para melhor compreensão das discussões e interpretações, optou-se pela escrita narrativa do texto que teve como colabores duas crianças ( 01 menino e 01 menina) que por meio de uma roda de conversa expressaram as narrativas que envolveram os saberes adquiridos por meio da pesca artesanal e o mito sobre o índio encantado no lago do Segredo. A vivência, os detalhes apresentados na narrativa e a relação com a atividade da pesca foram os critérios que os definiram enquanto colaboradores na pesquisa.

Enquanto técnica auxiliar também foi utilizada a entrevista semiestruturada, por ser esta a que permite compreender o significado atribuído pelos sujeitos a eventos, situações, processos ou personagens que fazem parte de sua vida cotidiana (DEMO, 2001).

Para preservar a identidade das crianças, utilizarei nomes dos deuses que representam o sol e a lua na mitologia tupi guarani - Jaci e Guaraci- considerando a importância que os elementos naturais tem para a pesca e para os povos tradicionais.

As narrativas serão apresentadas por meio de episódios e tratados a luz da análise de conteúdo, evidenciando a importância dos saberes, a transmissão entre as gerações e a percepção das crianças na manutenção de sua cultura e identidade.

\section{PRÁTICAS SOCIOAMBIENTAIS E A CONSTRUÇÃO DOS SABERES DA TRADIÇÃO EM COMUNDADES DE PESCADORES ARTESANAIS}

Compreende-se que os saberes são adquiridos por meio das relações humanas com seus ambientes, dentro de um determinado contexto e são transmitidos de pais para filhos, através de um aprendizado vivo e contínuo. Esses elementos se configuram dentro da definição apontada por Silva (2010) quando diz que os saberes são gerados a partir da vivência e convivência, apreendidos por meio das ações cotidianas e que são responsáveis pela conservação cultural dos povos.

Assim, a partir do universo conceitual de saberes, optou-se por trazer o conceito de saberes da tradição ${ }^{3}$. Trata-se dos saberes adquiridos por meio da convivência e da interação do ser humano com a natureza. "E que ao longo dos tempos as comunidades tradicionais têm desenvolvido e sistematizado o que lhes permitem responder a problemas de ordem material ligados à natureza e seus recursos e ainda ligados a ordem mítica e simbólica" (ALMEIDA, 2010, p.57).

São saberes que se traduzem na leitura diferenciada dos fenômenos, na interpretação de situações que cotidianamente exigem respostas mais imediatas e que são construídos, sobretudo, por meio das práticas socioambientais muito presentes e de valor acentuado nas comunidades tradicionais. Principalmente aquelas que mantém suas práticas econômicas ancoradas em modos de vidas que são conduzidas e organizadas pela relação socioambiental, como a pesca artesanal, muito comum em grande parte da nossa região norte, pela localização próxima do litoral e de rios e lagos.

\footnotetext{
3 Alguns autores denominam de Saber ambiental (LEFF, 2005); conhecimento cotidiano (LOPES, 1999); conhecimento popular (BRANDÃO, 2007); saberes primevos (CHASSOT, 2000), saberes tradicionais (DIÉGUES, 1994) como sinônimos ou com premissas semelhantes. Utilizarei esse conceito com base na epistemologia do termo abordada por Maria da Conceição de Almeida, (2010).
} 
Pois a água tem uma importância fundamental na constituição econômica das populações, pois trata-se de uma relação estabelecida desde os primórdios da história. Mas a pesca, não é apenas um meio econômico ou uma simples atividade humana. Para Moraes (2005), trata-se de um conjunto de relações de domínios variados que envolve uma multiplicidade de saberes, de fazeres e de instrumentos utilizados.

É dessa perspectiva que entendo, que na comunidade Segredinho, a pesca associa todos estes elementos e se mantém como propulsora da cultura e da identidade local, pois no exercício desta atividade, os moradores "estabelecem distintas formas de leitura de mundo" (ALMEIDA, 2017, p. 53).

Uma destas formas diferenciadas de interpretar e explicar os fenômenos são os mitos, que possuem uma forte presença na comunidade Segredinho. Por meio deles os moradores interpretam a si próprios, o seu passado e a sociedade em que vivem e encontram soluções para o desconhecido. Aliando a isso, suas crenças religiosas e as relações que estabelecem entre si e entre os saberes que vão constituindo, recriando e transmitindo para as novas gerações.

Segundo Eliade (1972, p. 109), "o mito não é absolutamente uma teoria abstrata ou uma fantasia artística, mas uma verdadeira codificação da religião primitiva e da sabedoria prática". E por meio destes, revelam importantes elementos que condicionam e mantém as relações entre os seres sobrenaturais e os seres humanos.

Além dos mitos, encontram-se muitos saberes que são elaborados e construídos por meio da pesca artesanal, por essa atividade favorecer uma aproximação constante e ampla com a natureza. São estes:

O conhecimento de ventos, das águas, marés, fundos submarinos, correntes, hábitos de peixes, dentre uma série de processos que são "naturalizados" e formam redes cognitivas próprias para a interpretação, apropriação e representação destes processos que por vezes são considerados saberes (CARDOSO, 2001, p. 86).

Na comunidade, a convivência com o lago tem possibilitado a construção de saberes sobre os tipos de peixes e seus hábitos alimentares, a adequação dos instrumentos de acordo com o tipo de peixe a ser capturado, o tempo e as estações mais favoráveis, a localização dos cardumes, dentre outras habilidades que operam de forma prática e diferenciada do conhecimento científico. Além disso, existe "diálogo e complementaridade entre o real e imaginário que configura seu modo de vida" (MORAES, 2005, p. 149).

Esses saberes apreendidos por meio da observação, do acompanhamento e da realização constante da atividade da pesca tem favorecido o aprendizado das crianças, que envolvidas e em interação com a atividade vão constituindo seu corpus de saberes também sobre a anatomia dos peixes, os instrumentos de pesca, os hábitos alimentares dos peixes, os pontos de pesca do lago, as espécies e etc. Juntamente com o conhecimento sobre o mito que circunda o ambiente e as histórias que vivenciam e a experimentam envolvendo o índio encantado no lago.

Segundo Moraes (2005, p. 119), "os seres das águas, das florestas, dos vales, seres encantados, são elementos que dão significados e que fazem da pesca uma confluência entre o real e o imaginário". É nessa teia de relações que está configurado o universo que compõem a vida dos moradores da comunidade Segredinho. Que são mantidas e recriadas por meio das narrativas, contadas tanto por adultos quanto por crianças, pois elas desde cedo vão aprendendo a respeitar e a conviver com seres naturais e míticos, atribuindo uma importância fundamental para sua sobrevivência e a conservação dos elementos naturais presentes no lago.

Para Alves (2008, p. 39), "os mitos formam a consciência social. Com base neles, desenvolve-se toda uma concepção teórica sobre o sentido da vida, do viver, do morrer, e da existência do mundo". Por isso, a necessidade de respeitar, difundir e compartilhar estes saberes construídos pelas comunidades tradicionais, como uma estratégia de conhecimento 
diferenciada, que tem estrutura própria, singular e específica, portanto, assentados na complexidade e em múltiplas dimensões.

Os saberes têm suas raízes na tradição e, durante o exercício constante da ação sobre determinados fatos e fenômenos que se dão principalmente pela relação de troca entre seus membros, essa tem sido a condição primeira de transmissão e manutenção dos conhecimentos nas comunidades tradicionais. Pois, a relação de troca e o convívio estabelecido entre os moradores - pescadores e pescadoras, adultos e crianças - objetiva perpetuar os ensinamentos e ressignificá-los diante da realidade que está posta.

\title{
2 A PERCEPÇÃO DAS CRIANÇAS SOBRE OS SABERES DA TRADIÇÃO DA COMUNIDADE SEGREDINHO/CAPANEMA-PA
}

Segundo Moraes (2005) a produção do conhecimento se dá em distintos lugares, de formas variadas e com sistemas próprios de concepção. A pesca é um universo que apresenta um espaço frutífero e altamente rico em conhecimentos específicos de leitura do mundo. Mas para isto, é necessário estabelecer diálogos entre as gerações, no processo constante de transmissão, feito pela aproximação, acompanhamento e observação da atividade, através da ação, na qual experimentam, contrastam, atualizam e possam adquirir novos saberes, que vão servir para confirmar ou modificar alguma crença, possibilitando um contínuo aprendizado.

Elementos muito perceptíveis na comunidade Segredinho, em que as crianças estão sempre próximas aos pais/mães durante as pescarias ou acompanhando as conversas que envolvem as narrativas sobre o mito local. E isso, torna-se um aspecto importante de aprendizado e manutenção da cultura local, como foi possível identificar nas narrativas que serão descritas e analisadas a seguir:

Episódio 1:

\begin{abstract}
Sabe moça, um dia eu fui pro lago com a mamãe, fomos umas 09 horas e voltamos umas 17:00 horas, ela pesca lá e me levou, eu sempre vou com ela, gosto muito de ir lá. E aí quando a gente tava pescando a canoa virou, a gente se alagou, minha mãe ficou com medo, pois tava fundo onde a gente tava, mas minha prima me ajudou e me puxou de volta pra dentro da canoa. A mamãe ficou com medo de eu morrer, mas eu me virava, eu sei nadar, não tenho medo não, não tenho medo das histórias que contam sobre o lago e nem do índio que mora lá, sei que ele só faz mal pra quem maltrata o lago, escangalha as árvores. Depois disso, resolvemos ir embora, pois já tinha um pouco de peixe e tava ficando tarde. Pergunta da pesquisadora: E vocês não tem medo do índio encantado no lago? Ela respondeu: "não, ele só assusta se mexer com ele". A pesquisadora insistiu: como mexer com ele? A menina continuou: "tem que entrar caladinho, não perturbar ele, não fazer maldade com o lago, se não ele afunda a canoa da gente. A pesquisadora brincou: Será que não foi ele que alagou a canoa de vocês? Ela retrucou: "não, ele conhece a gente, sabe que a gente é da comunidade e só vai pescar". (Jaci, 10 anos).
\end{abstract}

É possível inferir deste episódio que Jaci, que é moradora da comunidade assim como sua família conhece sobre o mito do índio e demonstra respeito por esse saber mantido pelos moradores da comunidade e que embora ainda criança já desenvolveu seu entendimento e firmou suas posições sobre o mito.

O que se configura no que Moraes (2008) fala, que os saberes construídos e metamorfoseados culturalmente são transmitidos para as novas gerações como um processo educativo que se vale de todos os elementos constituintes, sejam eles míticos e imaginários ou práticos e materiais. Quando ela afirma: "não tenho medo das histórias que contam sobre o lago", confirma que esta tradição é contada e recontada pelos mais idosos. Ou seja, acentua a permanência dos saberes da tradição por meio das narrativas orais. 
Segundo Alves (2008), a narrativa é tão importante para a vida humana que é impossível imaginar um mundo sem ela, um mundo sem histórias, mitos, contos ou dramas. Esse universo que envolve imaginação, tradição e saberes contribui para conservação e manutenção dos mitos da comunidade que mesmo as crianças sempre tem uma história para contar sobre o lago.

Nesse caso também, vimos que Jaci, descreve a partir de uma experiência que ela viveu, o que também é muito comum entre as crianças, pois eles acompanham seus pais e mães constantemente ao lago e vivem suas experiências. Para Larrosa (2010, p.34), a experiência é entendida como uma expedição em que se pode escutar o "inaudito" e em que se pode ler o não lido, isso é, um convite para romper com as regularidades de um sistema que já dá um mundo interpretado e pronto.

Outro elemento que chama a atenção no episódio narrado por Jaci é com relação ao respeito e consideração que o índio tem com os moradores locais, quando ela diz que: "sei que ele só faz mal pra quem maltrata o lago, escangalha as árvores ”. Esse entendimento demonstra que para eles é necessário parcimônia ao entrar e estar no lago. Trata-se do que Morais (2008; p.132) conceitua como "precaução", ou seja, a crença de que o mito pode vir a ajudar ou prejudicar os pescadores caso não demonstrem respeito a essas crenças. O que colabora para a conservação e o uso equilibrado de seus recursos naturais por meio das práticas socioambientais.

Podemos ratificar mais uma vez que o lago do Segredo é parte integrante da vida da comunidade, quer seja por meio de seus recursos naturais, quer seja por meio dos saberes que são constituídos nele, ou seja, os moradores têm nas águas do lago, além de uma fonte de alimentação que faz parte do caráter prático e utilitário, pois a utilizam na atividade da pesca artesanal e também como uma fonte de referência simbólica e mítica.

E, portanto, caracterizam-se em uma forma diferenciada, mas não única nem inferior de ler o mundo e os fenômenos, além de configurarem uma maneira de compreender a vida e de compor a ciência e o conhecimento.

Episódio 2:

Eu moro aqui desde que nasci, eu tenho 12 anos, meu pai e minha mãe pescam, meu pai vai mais vezes, a mamãe só de vez em quando. Às vezes eu vou com eles, mas a mamãe diz que é perigoso, porque o lago é fundo. Se eles deixassem eu ia toda vez, eu também gosto de pescar, ficar no lago escutando o barulho do vento, botar a linha e esperar o peixe. A pesquisadora pergunta: qual o peixe que vc mais gosta? Eu gosto do traíra e do jacundá, de todos (risos), as vezes a gente pode se confundir com os peixes, eles são bem parecidos, mas eu já sei dizer o nome certo deles, já sei porque fico vendo o papai separar e dá o nome. Já sei que a anujá tem o rabo diferente do jacundá. Meu pai conhece todos eles, sabe a diferença deles. No inverno, a gente não vai pro lago porque fica muito cheio e os peixes descem é mais difícil pegar e aí as coisas ficam mais ruim, a gente come mais é carne e frango. (Guaraci, 12 anos).

No episódio acima, enfatiza-se a importância dos saberes da tradição apreendidos pelas crianças, mas aqui a conotação é dada aos saberes que são gerados e apreendidos por meio da atividade da pesca que é realizada no Lago do Segredo, mais uma vez, este ambiente congrega uma série de elementos formativos constituintes da composição social, cultural, econômica e mítica da comunidade.

$\mathrm{Na}$ narrativa, está presente também a transmissão dos saberes por meio do acompanhamento e da vivência das práticas entre as diferentes gerações. Tal organização é muito comum e presente nas comunidades que tem na pesca sua atividade econômica principal. Para Farias (2006; p.47), "essa transmissão, feita de geração em geração, de forma oral ou prática, constitui-se no conjunto de testemunhos, conservados ou desaparecidos que materializam a vida de uma sociedade". Assim, são incorporados e compreendidos os sentidos e fenômenos extraídos por meio da convivência e da observação constante de uma atividade. 
As crianças da comunidade convivem diretamente com os adultos e compartilham de suas atividades. É comum ver ao lado dos pescadores e pescadoras as crianças, em uma espécie de parceria e colaboração na realização da pesca, o que potencializa a construção de aprendizagens que se dão por meio da observação, da imitação e do compartilhamento das experiências.

Os saberes são adquiridos de forma espontânea, sem um compromisso prévio, um rigor ou uma obrigatoriedade, mas no exercício das práticas do cotidiano e na construção de sua cultura. De acordo com D’ambrósio (2001, p. 22):

O cotidiano está impregnado dos saberes e fazeres próprios da cultura. A todo instante, os indivíduos estão comparando, classificando, quantificando, medindo, explicando, generalizando, inferindo e, de algum modo, avaliando, usando os instrumentos materiais e intelectuais que são próprios à sua cultura.

Trata-se portanto, de um processo educativo que envolve interação, comunicação, diálogo e experimentação de tudo que é vivido, percebido e inventado para gerar o saber, que é diferenciado mas não menor ou inferior ao conhecimento cientifico, possui estratégia e organização especifica, são saberes distintos que podem ser complementares.

Quando, em sua narrativa Guaraci diz: "Já sei que a anujá tem o rabo diferente do jacundá. Meu pai conhece todos eles, sabe a diferença deles". Ele confirma a assertiva de que a experiência também produz conhecimento, que vai ter importância no seu dia a dia, vai ter sentido e significado nos seus hábitos alimentares, na economia local e na conservação da cultura e da pesca na comunidade. Não se trata de um aprendizado adquirido nos manuais escolares mas no cotidiano, na experiência constante com a pesca e com os peixes.

O conhecimento adquirido por Guaraci sobre as espécies de peixes existentes no lago, a estrutura de cada um, seus contornos, hábitos alimentares e até as diferenças já apreendidas por meio da convivência, subsidia um saber que é prático. Pois foi construído por meio da observação e das transmissões construídas entre as gerações de forma solidária e coletiva. É o que denomina Lévi- Strauss (1989, p.98) de "a ciência do concreto".

Percebi também por meio do episódio, que Guaraci está inserido dentro do contexto econômico que a família desenvolve e isso lhe possibilita está integrado de forma participativa e formativa nesses espaços, o que lhe favorece o entendimento da realidade que se movimenta, que é modificada pelas ações humanas mas que também contribui para a transformação das pessoas, por meio da relação com a natureza aprendem a respeitar o tempo, as estações, o ambiente natural e seus mistérios.

Quando ele ressalta: "no inverno, a gente não vai pro lago porque fica muito cheio e os peixes descem é mais difícil pegar e aí as coisas ficam mais ruim”. Demonstra seu letramento diante do mundo, sua compreensão diante das dificuldades e de como os moradores precisam se adaptar as contingências da natureza. Ou seja, há uma apreensão de sua realidade, apreender no sentido de aprender proposto por Freire (1996, p. 69) "aprender para nós é construir, reconstruir, constatar para mudar, o que não se faz sem a abertura ao risco e a aventura do espírito".

Assertiva que é importante dentro do contexto sociocultural, pois congrega um sentido transformador tanto de si quanto de sua realidade. Embora, os moradores sofram as privações ocasionadas pelo tempo que a natureza necessita para se recompor, eles desenvolvem a consciência de que esse momento é temporário e que precisam realizar outras atividades econômicas para sobreviver, do contrário, sua sobrevivência estaria em risco pelo esgotamento dos recursos.

Compreende-se assim, o desenvolvimento de uma responsabilidade coletiva pela conservação dos recursos naturais, na maioria das vezes, orientada e reproduzida por meio dos 
saberes, pois são estes que condicionam suas atitudes e os mantém integrados a um modo de vida pautado na preservação e no equilíbrio com o ambiente.

Brandão (2007, p.75) ressalta que, dentro de sua cultura, em sua sociedade, as pessoas aprendem de maneira mais ou menos intencional, através do envolvimento dentro do corpo, da mente e da afetividade, entre as incontáveis situações de relações e de trocas entre os homens, é parte do processo pessoal de endoculturação e é também parte da aventura humana de 'tornase pessoa'.

Portanto, são inúmeras as possibilidades de saberes ligados a pesca e aos mitos que permeiam o contexto das comunidades tradicionais e colaboram para alicerçar a cultura e a identidade dos povos, principalmente no cenário amazônico em que nos encontramos. Jaci e Guaraci são apenas duas crianças que, apesar da pouca idade, já apresentam uma riqueza de conhecimentos que fazem diferença em seus modos de vida e na relação com o Lago do Segredo. O que evidencia que a pesca tem o significado e a importância na comunidade que vai além da necessidade econômica, mas configura-se no modo de vida da população através de suas tradições, crenças e simbologias, elementos presentes no seu universo sociocultural.

\section{CONSIDERAÇÕES FINAIS}

Compreender os saberes da tradição da comunidade Segredinho a partir da percepção de duas crianças, moradores da comunidade, representou também dar visibilidade as práticas socioambientais que são realizadas nas comunidades tradicionais e as crenças, mitos e costumes que estas potencializam, principalmente no cenário amazônico pela sua sociobiodiversidade.

O contexto da comunidade Segredinho é diferenciado não apenas pela preponderância dos elementos naturais presentes no Lago do Segredo mas sobretudo, pela exuberância de saberes que são apreendidos por meio da relação com ele. E a pesca é um dos mecanismos que viabiliza essas aprendizagens, não somente para os adultos mas também para as crianças que desde cedo vão para o Lago acompanhar seus pais e mães nas pescarias.

Foi perceptível que Jaci e Guaraci conhecem os segredos da pesca e do mito que circundam o ambiente e cotidianamente desenvolvem saberes ligados a; composição, tamanho, tipo dos peixes, os instrumentos mais adaptados a cada peixe, a identificação das espécies, os pontos mais propícios para a pesca e etc. Saberes adquiridos por meio da transmissão e da observação dos mais experientes na atividade, que passa de geração a geração e de pai/mãe para filho e filha.

Sobre o mito do índio encantado no lago, as crianças demonstraram respeito, consideração e apreço pelas histórias contadas pelos mais velhos e reproduzem estas atitudes através de suas próprias experiências. Isso se torna importante à medida em que consolida a cultura e a identidade desta comunidade, que por meio desta geração poderá manter suas tradições e conservar seus valores, através dos comportamentos que são modificados em virtude da crença no mito.

Por meio do reconhecimento da existência do índio encantado no Lago as crianças desenvolvem atitudes de preservação ao meio ambiente, respeito ao período de reprodução dos peixes e só retiram do lago o suficiente para seu sustento, ou seja, o mito influencia na tomada de ação frente as suas necessidades econômicas. Evidenciando, um saber que se concretiza culturalmente, socialmente e economicamente por meio da organização e do consumo consciente.

O reconhecimento da tradição local demonstrado pelas crianças é de suma importância pois convalida uma cultura que se constrói em diferentes percepções de compreender e interpretar o mundo, expandindo a consciência para outras formas de fazer ciência, que se projeta nas relações, na experiência e na diversidade, o que materializa a capacidade do ser humana de aprender com a natureza sem contudo, destruir seus recursos. 
Ressalto ainda, que os resultados discutidos neste artigo corroboram para divulgar e valorizar os modos de vida das comunidades de pescadores artesanais que por meio dos saberes da tradição criam e recriam seus modos de vida, constroem suas narrativas, estruturam as regras que norteiam o seu comportamento e dão significados aos acontecimentos cotidianos. Tudo isso, dentro de uma configuração que dialoga com os aspectos materiais da vida, ligados a sua sobrevivência e a sua imaterialidade, ou seja, a imaginação, o mito, a criatividade e o encantamento diante do desconhecido.

\section{REFERÊNCIAS}

ALMEIDA, Maria da Conceição de. Complexidade, saberes científicos, saberes da tradição. São Paulo: Editora Livraria da Física: 2010.

ALMEIDA, Maria da Conceição de. Ciências da complexidade e educação: razão apaixonada e politização do pensamento. 2. ed. Curitiba: Appris, 2017.

ALVES, L. M. S. A. A tradição oral na Amazônia: a mitopoética dos espaços nas narrativas, visagens e assombrações. In: ALVES, M. L. A. et al. (Org). Cultura e educação: reflexões para a prática docente. Belém: EDUFPA, 2008. p. 24-47.

BRANDÃO, Carlos Rodrigues. O Que é educação. São Paulo: Brasiliense, 2007. 116 p.

CARDOSO, Maria Bárbara da Costa. Saberes ribeirinhos quilombolas e sua relação com a educação de jovens. São Paulo: Moderna, 2001.

CHASSOT, Attico. Alfabetização cientifica: questões e desafios para a educação. Ijuí-RS: Editora Unijuí, 2000.

D`AMBROSIO, Ubiratám. Educação para uma sociedade em transição. São Paulo: Papirus, 2001.

DEMO, Pedro. Pesquisa: o princípio cientifico e educativo. 8. ed. São Paulo: Cortez, 2001.

DIÉGUES, Antônio Carlos. O mito moderno da natureza intocada. São Paulo, NUPAUB, Universidade de São Paulo, 1994.

ELIADE, Mircea. Mito e realidade. São Paulo: Perspectivas, 1972.

FARIAS, Carlos Aldemir. Alfabetos da alma: histórias da tradição na escola. Porto Alegre: Sulina, 2006.

FURTADO, Lurdes. Pescadores do Rio Amazonas: Um estudo antropológico da pesca ribeirinha numa área amazônica. Belém-PA: Museu Paraense Emílio Goeldi,1993.

Citação no texto: Furtado (1993)

FREIRE, Paulo. Pedagogia da autonomia. São Paulo: Paz e Terra, 1996.

LARROSA, Jorge. Pedagogia profana: danças, piruetas e mascaradas. 5. ed. Belo Horizonte: Autêntica, 2010. 
LEEF, Henrique. Saber ambiental: sustentabilidade, racionalidade, complexidade, poder. 4. ed. Rio de Janeiro: Vozes, 2005.

LÉVI-STRAUSS, Claude. A ciência do concreto. In: O Pensamento Selvagem. Tradução de Tânia Pellegrini, Campinas, SP: Papirus, 1989.

LOPES, Alice R. Cassimiro. Conhecimento escolar: ciência e cotidiano. Rio de Janeiro: EDUERJ, 1999.

MINAYO, Maria Cecília de Souza (org). Pesquisa Social: teoria, método e criatividade. Petrópolis, RJ: Vozes, 2016.

MORAES. Sérgio Cardoso de. Saberes da Pesca: Uma arqueologia da ciência da tradição. 2005. Tese (Doutorado em educação) - Universidade Federal do Rio Grande do Norte. Centro de Ciências Sociais Aplicada: Natal, 2005.

MORAES, Sergio Cardoso de. Fragmentos de saberes tradicionais. In: ALVES, M. L. A. et al. (Org.). Cultura e educação: reflexões para a prática docente. Belém: Edufpa, 2008. p. 109-132.

ROCHA, Nádia Suei Araújo da. A pesca feminina na comunidade Segredinho: município de Capanema-PA. 2011. Dissertação (Mestrado em Gestão de Recursos Naturais) - Programa de Pós-Graduação em Gestão de Recursos Naturais e Desenvolvimento Local, Universidade Federal do Pará, Belém, 2011.

SILVA, Márcia Regina Farias da. Ciência, natureza e sociedade: diálogo entre saberes. São Paulo: Livraria da Física, 2010. 